\title{
IMPLEMENTASI FUZZY MAMDANI DALAM PENENTUAN BESARAN DISKON
}

\author{
Dyah Ayu Irawati', Rudy Aryanto ${ }^{2}$, Herlina Prastiwi $^{3}$ \\ 1,2,3 Teknik Informatika, Teknologi Informasi, Politeknik Negeri Malang \\ dyah.ayu@polinema.ac.id ${ }^{1}$, rudy.ariyanto@polinema.ac.id ${ }^{2}$, herlina.prastiwi@gmail.com ${ }^{3}$
}

\begin{abstract}
Abstrak
Bisnis yang cocok di era milenial adalah bisnis laundry. Selain menentukan strategi persaingan dengan kompetitor, selanjutnya bagaimana menarik minat pelanggan untuk lebih sering menggunakan jasa mereka, sampai akhirnya mau merekomendasikan jasa ini kepada relasi mereka. Promosi yang dapat dilakukan adalah dengan memberikan diskon kepada member laundry yang aktif mencuci pada tiap bulannya. Penentuan besaran diskon kepada member memperhatikan dua aspek, yaitu jumlah frekuensi mencuci dan total bayar yang dihitung per bulan yang diolah dengan sistem inferensi Fuzzy Mamdani. Berdasarkan hasil uji coba penentuan besaran diskon menggunakan metode fuzzy mamdani, menunjukkan bahwa besaran diskon akan meningkat secara berkala berdasarkan akumulasi frekuensi mencuci dan total bayar per bulan dimana kedua aspek tersebut saling mempengaruhi satu dengan yang lainnya.
\end{abstract}

Kata kunci : Laundry, Diskon, Sistem Inferensi fuzzy Mamdani

\section{Pendahuluan}

Salah satu bisnis yang cukup menjanjikan adalah bisnis laundry. Bisnis ini sangat cocok di era milenial. Beban kerja dan kesibukan yang makin meningkat membuat para generasi milenial mencari layanan jasa yang dapat mempermudah kegiatan harian mereka. Mencuci pakaian pun menjadi persoalan tersendiri. Dengan permasalahan yang timbul, hal itu menjadi peluang bisnis yang menjanjikan sehingga banyak bisnis laundry baru yang bermunculan.

Bagi para pelaku bisnis laundry tentunya harus menentukan strategi persaingan dengan kompetitor dimana mereka juga harus menentukan strategi bagaimana menarik minat pelanggan untuk lebih sering menggunakan jasa mereka, sampai akhirnya mau merekomendasikan jasa ini kepada relasi mereka. Salah satu cara promosi yang dapat dilakukan adalah dengan memberikan diskon.

Diskon dapat diberikan dengan berbagai bentuk potongan harga. Diskon yang diberikan pada umumnya dalam bentuk penambahan kuantitas, diskon pembayaran tunai/cash. Diskon kuantitas berupa tambahan gratis produk tertentu setelah terjadi pembelian dalam jumlah tertentu. Diskon pembayaran tunai adalah pengurangan pembayaran jika melampaui target tertentu. Dalam hal ini, pemilik laundry ingin memberi diskon berupa berupa potongan harga dalam bentuk persen kepada member laundry yang aktif mencuci pada tiap bulannya yang didapat pada tiap transaksi yang dilakukannya.

Selanjutnya, untuk mengetahui faktor yang mempengaruhi pemberian diskon, maka telah dilakukan survei kepada sekitar 240 responden dan dapat disimpulkan bahwa terdapat dua faktor utama pemberian diskon, yaitu loyalitas pelanggan yang dihitung berdasarkan frekuensi transaksi dan besaran total bayar yang dibayarkan untuk transaksi laundry yang diakumulasi selama per bulan. Penetuan maksimal besaran dari diskon tersebut adalah $30 \%$ dari total transaksi sebelum diskon dengan asumsi bisnis yang ditentukan pemilik laundry hal itu setara dengan sistem diskon 7 kali cuci gratis 1 kali pencucian. Dari hal tersebut maka digunakanlah sistem inferensi Fuzzy Mamdani untuk menghitung penentuan besaran diskon untuk tiap member pada tiap transaksi di setiap bulan.

\section{Metode Penelitian}

Pengembangan sistem dilakukan dengan tahapan sebagai berikut : (paragraph)

- $\quad$ Studi Literatur, untuk mempelajari konsep logika fuzzy dan penunjang dalam pengembangan sistem berbasis web.

- Analisis Sistem, mempelajari dan menganalisa proses atau alur kerja Sistem Inferensi Fuzzy Mamdani.

- Pembuatan Aplikasi, menyusun rancangan sistem berdasarkan pada data yang diperoleh dari tahap analisis sistem. Pada tahap ini dilakukan perancangan basis data (MongoDB) dan perancangan tampilan (interface), yang dilanjutkan dengan pembuatan sistem dengan menggunakan ReactJS sebagai frontend dan Express-NodeJS sebagai backend.

- Pengujian, aplikasi diuji coba dengan suatu kasus untuk mengetahui bahwa sistem inferensi fuzzy telah mampu memproses dan menghasilkan

Sistem inferensi fuzzy dapat direpresentasikan sesuai dengan Gambar 1 berikut, 


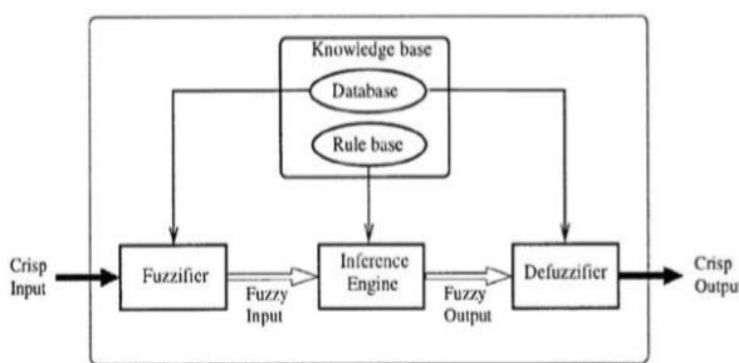

Gambar 1. Proses Sistem Inferensi Fuzzy

Dalam prosesnya melibatkan 3 tahap: Fuzzifikasi, Inferensi, Defuzzifikasi[1].

- Fuzzifikasi: Kumpulan data yang tegas dikonversi menjadi kumpulan fuzzy yang dapat diinterpretasikan oleh mesin inferensi.

- Inferensi: Dibutuhkan input fuzzy yang dihasilkan oleh proses fuzzifikasi dan menghasilkan output berdasarkan pada basis aturan yang diamankan dari basis data pengetahuan. Output dari tahap ini juga dalam bentuk fuzzy.

- Defuzzifikasi: Set data fuzzy kemudian dikonversi kembali ke set crisp, di mana nilai keanggotaan menempati 1 .

Basis pengetahuan sangat penting untuk berfungsinya semua tahap. Fuzzifier menggunakan database untuk mendefinisikan fungsi keanggotaannya, mesin inferensi menggunakan basis aturan dan defuzzifier menggunakan output database untuk menghasilkan nilai-nilai tegas.

\section{Hasil Dan Pembahasan}

Metode Mamdani sering dikenal dengan nama Metode Min-Max. Metode ini diperkenalkan oleh Ebrahim Mamdani pada tahun 1975[2]. Pada sistem inferensi fuzzy mamdani, keputusan yang biasa dilakukan oleh para ahli digunakan sebagai aturan fuzzy dalam mengambil keputusan atas masukan yang diterima. Aplikasi yang telah dibangun mampu untuk memecahkan permasalahan-permasalahan yang diselesaikan dengan menggunakan logika fuzzy. Pengguna dapat mengubah, menambah ataupun menghapus variabel, himpunan, aturan fuzzy yang akan digunakan sehingga sistem ini sangat fleksibel untuk digunakan dalam memecahkan berbagai permasalahan.

\subsection{Fuzzifikasi}

Pembentukan himpunan Menentukan variabel yang terkait dalam proses yang akan ditentukan dan fungsi fuzzifikasi yang sesuai. Pada kasus ini , ada 3 variabel yang akan dimodelkan, yaitu :

1. Loyalitas, terdiri atas 3 himpunan fuzzy, yaitu RENDAH, SEDANG dan TINGGI. Berikut gambar grafik fungsi keanggotaannya:

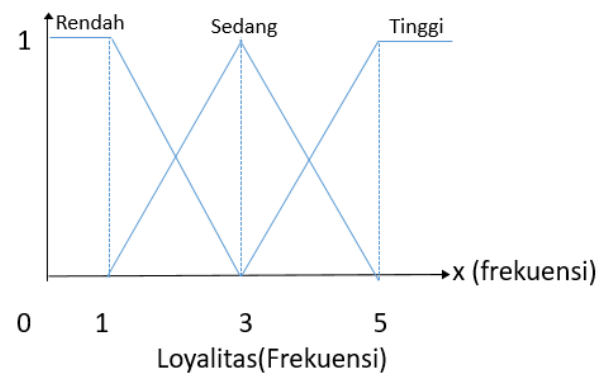

Gambar 2. Grafik Fungsi Keanggotaan Loyalitas

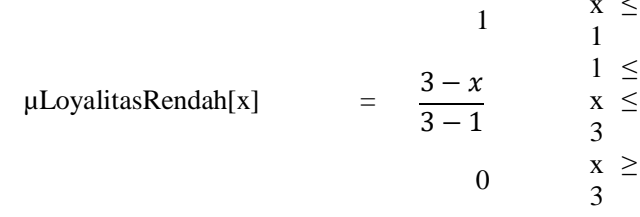

$$
\begin{aligned}
& \begin{array}{l}
\mathrm{x} \leq \\
1
\end{array} \\
& 0 \text { atau } \\
& \begin{array}{ll} 
& \mathrm{x} \geq \\
& 5 \\
& 1 \leq
\end{array} \\
& \mu \text { LoyalitasSedang }[\mathrm{x}] \quad=\frac{x-3}{5-3} \quad \mathrm{x} \leq \\
& \begin{array}{ll}
5-x & 3 \leq \\
\hline 5-3 & \mathrm{x} \leq \\
& 5
\end{array} \\
& \begin{array}{rll}
0 & \mathrm{x} \leq \\
& 3 \\
& 3 \leq \\
& x-3 & \mathrm{x} \leq \\
5-3 & 5 \\
& \mathrm{x} \geq \\
& 5
\end{array}
\end{aligned}
$$

Mencari fungsi keanggotaan di $\mathrm{x}=1$,

$\mu$ LoyalitasRendah[1] $=1$

$\mu$ LoyalitasSedang[1] $=0$

$\mu$ LoyalitasSering $[1]=0$

2. Total bayar, terdiri atas 3 himpunan fuzzy, yaitu RENDAH, SEDANG dan TINGGI.

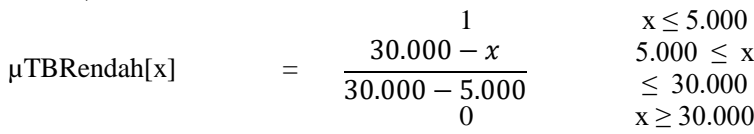

$$
\begin{aligned}
& x \leq 5.000 \\
& \text { atau } x \geq \\
& 55.000 \\
& \begin{array}{ccc}
\mu \text { TBSedang }[\mathrm{x}]= & x-5.000 & 5.000 \leq \mathrm{x} \\
& \frac{50.000-5.000}{55.000-x} & \leq 30.000 \\
& \frac{30.000 \leq}{55.000-30.000} & \mathrm{x} \leq \\
& 50.000
\end{array} \\
& \mu \text { TBTinggi[x] } \quad=\begin{array}{cc}
0 & x-30.000 \\
\frac{x}{55.000-30.000} & 30.000 \leq \\
1 & \mathrm{x} \leq 55.000 \\
& \mathrm{x} \geq 55.000
\end{array}
\end{aligned}
$$

Mencari fungsi keanggotaan di $\mathrm{x}=12000$,

$\mu$ TBRendah[12000] $=0.72$

$\mu$ TBSedang[12000] $=0.28$

$\mu$ TBTinggi $[12000]=0$ 


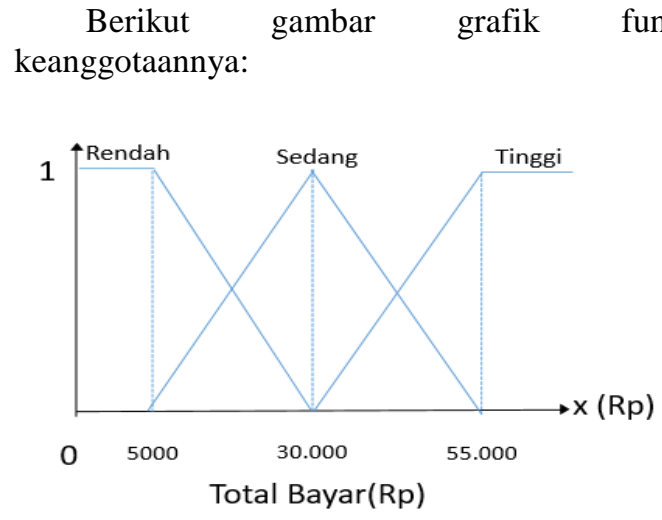

Gambar 3. Grafik Fungsi Keanggotaan Total Bayar

Berikut gambar grafik fungsi keanggotaannya:

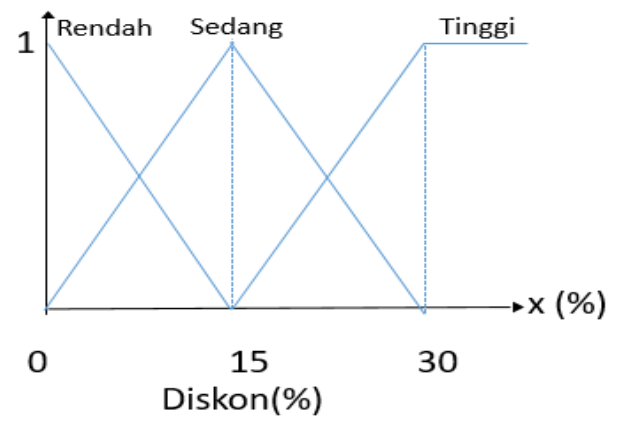

Gambar 4. Grafik Fungsi Keanggotaan Diskon

3. Diskon, terdiri atas 3 himpunan fuzzy, yaitu RENDAH, SEDANG dan TINGGI. Dibawah ini adalah fungsi keanggotaan berdasarkan Gambar 4.

$$
\begin{aligned}
& \mu \text { DiskonRendah }[\mathrm{x}] \quad=\quad \frac{15-x}{15-0} \\
& \mu \text { DiskonSedang }[\mathrm{x}] \quad=\quad \frac{x-0}{15-0} \\
& \frac{30-x}{30-15} \\
& \mu \text { DiskonTinggi }[\mathrm{x}] \quad=\quad \begin{array}{r}
0 \\
\frac{x-15}{30-15}
\end{array}
\end{aligned}
$$

1

\subsection{Inferensi}

Secara umum rules dibuat oleh pakar secara intuitif. Rules berupa pernyataan-pernyataan kualitatif yang ditulis dalam bentuk if then, sehingga mudah dimengerti. Inferensi merupakan proses evaluasi aturan fuzzy untuk menghasilkan output dari tiap aturan. Masing-masing aturan fuzzy menghasilkan sebuah nilai yang sesuai dengan inputan yang diberikan. Jika dalam aturan fuzzy terdapat disjungsi (OR), maka hasil dari aturan itu merupakan gabungan dari nilai fungsi keanggotaan yang dimasukkan, sedangkan jika terdapat konjungsi (AND), maka hasil dari aturan fuzzy akan berupa irisan nilai fungsi keanggotaan dari inputan [3].

Berikut ini adalah aturan-aturan inferensi yang dibuat dalam penentuan diskon :

- [R1] IF Loyalitas Rendah AND TB Rendah THEN Diskon rendah.

- [R2] IF Loyalitas Rendah AND TB sedang THEN Diskon sedang.

- [R3] IF Loyalitas Rendah AND TB Tinggi THEN Diskon sedang.

- [R4] IF Loyalitas sedang AND TB sedang THEN Diskon sedang.

- [R5] IF Loyalitas sedang AND TB Rendah THEN Diskon rendah.

- [R6] IF Loyalitas sedang AND TB tinggi THEN Diskon tinggi.

- [R7] IF Loyalitas tinggi AND TB tinggi THEN Diskon tinggi.

- [R8] IF Loyalitas tinggi AND TB sedang THEN Diskon sedang.

- [R9] IF Loyalitas tinggi AND TB rendah THEN Diskon sedang.

\subsection{Defuzzifikasi}

Defuzzifikasi menggunakan Metode Centroid (composite moment), dimana nilai crisp diperoleh dengan cara mengambil titik pusat $\left(\mathrm{d}^{*}\right)$ daerah output fuzzy. Nilai d* secara umum dirumuskan:

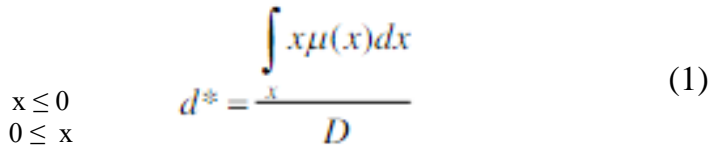

$$
\begin{aligned}
& \text { ऐimpana (1) didefinisikan sebagai berikut : } \\
& X^{2} \quad \text { : nilai output } \\
& d^{*} \leq 0 \quad \text { : titik pusat daerah fuzzy output } \\
& \text { 党然 } x^{\mathrm{x}} \text { : fungsi keanggotaan dari himpunan fuzzy } \\
& \text { output } \\
& \mathrm{D}_{15}^{\leq \mathrm{x}} \text { : luas daerah fuzzy output } \\
& \text { 3.430 Uji Coba }
\end{aligned}
$$

$\mathrm{x} \leq$ Setelah dilakukan runtutan perhitungan menggunakan sistem inferensi fuzzy mamdani maka dislapat uji coba dengan beberapa kondisi. Berikut ini pengeujian pada Tabel 1 adalah keadaan dimana jumlah frekuensi transaksi dan total bayar perbulan dalam rêftang rendah, maka akan menghasilkan besaran diskon yang rendah pula.

Tabel 1.Pengujian Frekuensi \& TB Rendah

\begin{tabular}{|c|c|c|}
\hline Frekuensi & TotalBayar & Diskon \\
\hline 1 & 10800 & $10 \%$ \\
\hline 1 & 11600 & $11 \%$ \\
\hline 1 & 13200 & $12 \%$ \\
\hline 1 & 17600 & $13 \%$ \\
\hline 2 & 18900 & $14 \%$ \\
\hline 2 & 29400 & $15 \%$ \\
\hline
\end{tabular}


Tabel 2. Pengujian Frekuensi Rendah \& TB Tinggi

\begin{tabular}{|c|c|c|}
\hline Frekuensi & TotalBayar & Diskon \\
\hline 1 & 55000 & $15 \%$ \\
\hline 2 & 32000 & $15 \%$ \\
\hline 2 & 36000 & $16 \%$ \\
\hline 2 & 40000 & $16 \%$ \\
\hline 2 & 45000 & $17 \%$ \\
\hline 2 & 50000 & $17 \%$ \\
\hline
\end{tabular}

Pada Tabel 2 diatas adalah keadaan dimana jumlah frekuensi transaksi rendah sedangkan total bayar perbulan tinggi, maka akan menghasilkan besaran diskon dalam rentang diskon sedang.

Berikut ini pada Tabel 3 adalah keadaan dimana jumlah frekuensi transaksi tinggi sedangkan total bayar perbulan rendah, maka akan menghasilkan besaran diskon dalam rentang diskon sedang.

Tabel 3. Pengujian Frekuensi Tinggi \& TB Rendah

\begin{tabular}{|c|c|c|}
\hline Frekuensi & TotalBayar & Diskon \\
\hline 3 & 15000 & $12 \%$ \\
\hline 3 & 18000 & $13 \%$ \\
\hline 3 & 21000 & $14 \%$ \\
\hline 4 & 28000 & $15 \%$ \\
\hline 5 & 25000 & $15 \%$ \\
\hline
\end{tabular}

Berikut ini pengujian pada Tabel 4 adalah keadaan dimana jumlah frekuensi transaksi dan total bayar perbulan tinggi, maka akan menghasilkan besaran diskon dalam rentang diskon yang tinggi pula.

Tabel 4. Pengujian Frekuensi \& TB Tinggi

\begin{tabular}{|c|c|c|}
\hline Frekuensi & TotalBayar & Diskon \\
\hline 3 & 36000 & $15 \%$ \\
\hline 3 & 45000 & $18 \%$ \\
\hline 4 & 44000 & $17 \%$ \\
\hline 4 & 54000 & $23 \%$ \\
\hline 5 & 50000 & $20 \%$ \\
\hline 5 & 55000 & $30 \%$ \\
\hline
\end{tabular}

Berikut ini pengujian pada Tabel 5 adalah keadaan dimana jumlah frekuensi transaksi terus meningkat dengan jumlah total bayar perbulan tetap tinggi, maka akan menghasilkan besaran diskon yang bervariasi.

Tabel 5.Pengujian Frekuensi bervariasi dan TB Tinggi

\begin{tabular}{|c|c|c|}
\hline Frekuensi & Total Bayar & Diskon \\
\hline 1 & 40000 & $15 \%$ \\
\hline 1 & 50000 & $15 \%$ \\
\hline 2 & 44000 & $17 \%$ \\
\hline
\end{tabular}

\begin{tabular}{|c|c|c|}
\hline Frekuensi & Total Bayar & Diskon \\
\hline 2 & 53000 & $17 \%$ \\
\hline 3 & 46000 & $18 \%$ \\
\hline 3 & 50000 & $20 \%$ \\
\hline 4 & 48000 & $19 \%$ \\
\hline 4 & 52000 & $20 \%$ \\
\hline 5 & 53000 & $23 \%$ \\
\hline 5 & 55000 & $30 \%$ \\
\hline
\end{tabular}

\section{Simpulan Dan Saran}

\subsection{Simpulan}

Besaran diskon akan meningkat secara berkala berdasarkan akumulasi frekuensi transaksi dan total bayar perbulan. Untuk mendapatkan besaran diskon maksimal maka frekuensi mencuci dan total bayar harus dalam rentang tinggi. Apabila frekuensi mencuci rendah dan total bayar tinggi dan sebaliknya maka akan menghasilkan besaran diskon dalam rentang sedang. Namun bila jumlah frekuensi mencuci dan total bayar rendah maka diskon yang dihasilkan juga rendah. Variabel input seperti frekuensi mencuci dan total bayar saling mempengaruhi dalam penentuan besaran diskon. Maka dari itu disarankan untuk pengaplikasian metode Fuzzy Mamdani dalam penentuan besaran diskon.

\subsection{Saran}

Aplikasi ini diharapkan dapat dimanfaatkan untuk menyelesaikan suatu permasalahan dengan logika fuzzy. Aplikasi ini juga dapat dimanfaatkan sebagai bahan pembelajaran untuk meningkatkan pengetahuan tentang logika fuzzy. Sistem ini masih terbatas pada penggunaan inferensi fuzzy dengan metode Mamdani. Diharapkan dapat dikembangkan untuk metode Tsukamoto, metode Sugeno, dan metode lainnya.

\section{Daftar pustaka:}

[1] Timothy J Ross, "Fuzzy Logic with Engineering Applications", 2nd ed., John. Wiley and Sons, Ltd pp. 13-15

[2] Kusumadewi, Sri \& Purnomo, Hari. 2010. Aplikasi Logika Fuzzy untuk Pendukung Keputusan Edisi 2. Yogyakarta: Graha Ilmu

[3] Lee, Kwang H. 2005. First Course on Fuzzy Theory and Application. Republic of South Korea. KAIST 